\title{
Experiment Study of Elasto-plastic Interactive Buckling of H-section Steel Beam-columns
}

\author{
Changgen Deng ${ }^{1}$, , Chenhui Zhang ${ }^{1}$, Fan Feng $^{1}$ and Jiang Zhou ${ }^{1}$ \\ ${ }^{1}$ Department of Structural Engineering, Tongji University, Shanghai 200092, China
}

\begin{abstract}
Six welded H-section steel specimens subjected to the axial compressive load, the in-plane shear force and the resulting bending moment around the cross-section major axis are tested monotonically to investigate the elastoplastic interactive buckling performances of beam-columns. The specimens are designed to fail due to local interactive buckling which is monitored by strain gauges and displacement meters. Strain curves and displacement curves varying with the shear force are illustrated, based on which the local interactive buckling is identified and the ultimate moment capacity of the specimen is extracted. The tests reveal that the local buckling of the web and flange in the compression zone occurs simultaneously resulting in the decrease of the ultimate moment capacity of the specimen. The normalized moment versus rotation curves are illustrated and compared in pairs to investigate the effects of the axial compression ratio, the flange width-thickness ratio and the web height-thickness ratio on the normalized ultimate moment capacity, which is defined as the ratio of the ultimate moment over the plastic moment. It is observed that the normalized ultimate moment capacity decreases remarkably as the axial compression ratio or the flange width-thickness ratio increases, but varies little as the web height-thickness ratio increases.
\end{abstract}

\section{Introduction}

H-section steel members are among the most widely used steel members composed of flat plates with advantages of economy, satisfactory performance, convenience of manufacture and fabrication, etc. However, H-section steel members built-up with thin plates are susceptible to interactive buckling.

In a H-section member, if the critical stress of the isolated web is not equal to those of the isolated flanges, the stronger plate with larger critical stress restrains the weaker plates, and the local buckling of the web and flanges occurs simultaneously and interactively, which is referred to as plate / local interactive buckling. Moreover, local buckling may initiate overall buckling because of reduction of stiffness of the buckled section, which is a case of local-overall interactive buckling.

The local buckling, post-buckling, and interactive buckling of cold-formed, thin-walled members [1,2] have been extensively investigated in the past, taking the buckling interaction effect into account mainly within the range of elastic deformation. The ultimate capacity should account for plate interactive buckling effect [2].

For H-section members with moderate width-thickness ratios, there exist buckling interaction between the web and flanges in the range of elasto-plastic deformation, which is referred to as elasto-plastic interactive buckling.

Theoretical investigations[3,4], experimental studies [3,5 8] and finite element analyses[9,10] were conducted for I- or H-section beams, columns and beam-columns.
Ren [3] studied the local-overall interactive buckling behavior and ultimate load of I-section steel columns. The results have shown that plate width-to-thickness ratio and column slenderness ratio have significant influences on the buckling behavior and ultimate capacity of the column, and local buckling or local-overall interactive buckling may bring about the column failure.

The ultimate moment capacity is related to different failure (post-buckling) modes developing from local buckling patterns, which is verified by Wang [8] and Cheng [10] with different kinds of post-buckling modes corresponding to different stress distribution affecting the moment capacity and different kinds of load-deformation hysteresis curves. So the interaction between the web and flanges indeed affects the ultimate moment capacity of $\mathrm{H}$ section beam-column.

Six welded H-section stub beam-columns subjected to combined axial compressive load and bending moment around the cross-section major axis have been tested under monotonic loading, as one set of a series of experimental studies on H-shaped and box-shaped steel beam-columns under monotonic and cyclic loading $[6,7,10,11]$, taking into account the elasto-plastic interactive buckling of the web and flanges on the ultimate moment capacities. In this paper, the experimental scheme is outlined, the experimental results and observations are summarized, and the effects of the axial compression ratio, the flange width-thickness ratio and the web height-thickness ratio on the normalized ultimate moment capacity of the beam-column are investigated. 


\section{Experimental scheme}

The specimen model extracted from a steel frame is simplified as a cantilevered stub beam-column, as shown in Figure 1, subjected to the vertical axial compressive load $P$, the horizontal in-plane shear force $F$ and the resulting bending moment around the cross-section major axis ( $z$ axis). The nominal length of each specimen is $L=1500 \mathrm{~mm}$. The horizontal in-plane displacement at the specimen top due to deformation is $\Delta=\Delta_{\mathrm{y} 1}-\Delta_{\mathrm{y} 2}-\theta_{\mathrm{b}} L$, where $\Delta_{\mathrm{y} 1}$ is the horizontal displacement at the specimen top and $\Delta_{\mathrm{y} 2}$ is the horizontal rigid displacement at the specimen base, and $\theta_{\mathrm{b}}$ is the rigid rotation of the specimen base. The nominal rotation of the specimen which is equivalent to the frame story drift angle is $\theta=\Delta / L$, and the moment at the specimen bottom is $M=F L$.

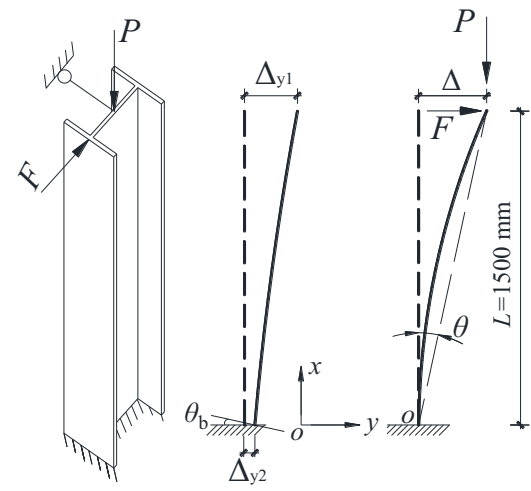

Figure 1. Applied loads and displacement patterns of the specimen.

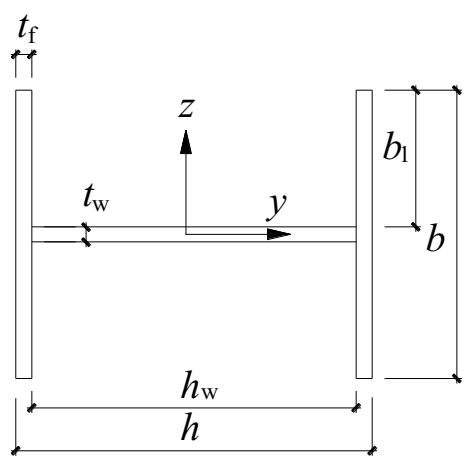

Figure 2. Built-up H-section dimensions.

Six H-section steel specimens are designed with design parameters listed in Table 1 , where $h, b, h_{\mathrm{w}}=h-2 t_{\mathrm{f}}$, $b_{1}=\left(b-t_{\mathrm{w}}\right) / 2, t_{\mathrm{w}}, t_{\mathrm{f}}$ are the H-section dimensions shown in Figure $2 ; h_{\mathrm{w}} / t_{\mathrm{w}}$ is the web height-thickness ratio, $b_{1} / t_{\mathrm{f}}$ is the flange width-thickness ratio; $f_{\mathrm{yk}}$ is the nominal yield
Table 1. Design parameters of the specimens.

\begin{tabular}{cccccccccc}
\hline Specimen & $\begin{array}{c}h \\
(\mathrm{~mm})\end{array}$ & $\begin{array}{c}b \\
(\mathrm{~mm})\end{array}$ & $\begin{array}{c}t_{\mathrm{w}} \\
(\mathrm{mm})\end{array}$ & $\begin{array}{c}t_{\mathrm{f}} \\
(\mathrm{mm})\end{array}$ & $h_{\mathrm{w}} / t_{\mathrm{w}}$ & $b_{1} / t_{\mathrm{f}}$ & $\begin{array}{c}f_{\mathrm{yk}} \\
(\mathrm{MPa})\end{array}$ & $\begin{array}{c}P_{\mathrm{n}} \\
(\mathrm{kN})\end{array}$ \\
\hline $\mathrm{H} 1-0.2$ & 300 & 160 & 6 & 8 & 47.3 & 9.6 & 235 & 0.2 & 200.4 \\
$\mathrm{H} 2-0.2$ & 300 & 160 & 6 & 6 & 48.0 & 12.8 & 235 & 0.2 & 171.5 \\
$\mathrm{H} 3-0.2$ & 300 & 160 & 5 & 6 & 57.6 & 12.9 & 235 & 0.2 & 157.9 \\
$\mathrm{H} 3-0.4$ & 300 & 160 & 5 & 6 & 57.6 & 12.9 & 235 & 0.4 & 315.8 \\
$\mathrm{H} 4-0.2$ & 300 & 200 & 5 & 6 & 57.6 & 16.3 & 235 & 0.2 & 180.5 \\
$\mathrm{H} 5-0.2$ & 350 & 160 & 5 & 8 & 66.8 & 9.7 & 235 & 0.2 & 198.8 \\
\hline
\end{tabular}

stress of steel; $n$ is the nominal axial compression ratio, and $P_{\mathrm{n}}=n f_{\mathrm{yk}} A$ is the nominal axial load, where $A$ is the nominal cross section area. All the specimens are built-up through penetration welding of thin plates of low alloy structural steel.

In order to investigate effects of the axial compression ratio, the flange width-thickness ratio and the web heightthickness ratio, the specimens are designed within three groups and five pairs: (1) pair H3-0.2 vs H3-0.4 with different axial compression ratios of the same section; (2) pair H1-0.2 vs H2-0.2 and pair H3-0.2 vs H4-0.2 with different flange width-thickness ratios with the same nominal axial compression ratio and about the same web height-thickness ratio each pair; (3) pair H1-0.2 vs H50.2 and pair H2-0.2 vs H3-0.2 with different web heightthickness ratios with the same nominal axial compression ratio and about the same flange width-thickness ratio each pair.

Measured H-section dimensions, the actual yield stresses of web $f_{\mathrm{yw}}$ and flanges $f_{\mathrm{yf}}$, and the section classification of individual web and flanges according to EC3 [12] are summarized in Table 2. The actually applied final axial load is equal to the nominal axial load $P_{\mathrm{n}}$.

The bottom of the specimen is welded to the stiffened base which is fixed on the strong reaction frame with high-strength bolts to achieve a fixed end.

The loading system contains a servo-controlled hydraulic actuator applying the horizontal load and a hydraulic jack applying the vertical axial load. A hinge joint is equipped between the specimen top and the hydraulic actuator and jack. The hydraulic jack is connected with an in-plane sliding device to allow the axial load follow the in-plane displacement at the specimen top and keep the vertical direction during the test.

The horizontal displacements at the top of specimens are measured by displacement meters on both sides of the actuator. The horizontal load $F$ versus the horizontal displacement $\Delta_{\mathrm{y} 1}$ curve is monitored to control the loading process, and the horizontal load versus out-ofplane displacement curve is monitored to prevent out-ofplane overall buckling. The out-of-plane displacements of all specimens are kept within $3 \mathrm{~mm}$.

Table 2. Measured parameters and section classification of the specimens.

\begin{tabular}{cccccccccccc}
\hline Specimen & $\begin{array}{c}h \\
(\mathrm{~mm})\end{array}$ & $\begin{array}{c}b \\
(\mathrm{~mm})\end{array}$ & $\begin{array}{c}t_{\mathrm{w}} \\
(\mathrm{mm})\end{array}$ & $\begin{array}{c}t_{\mathrm{f}} \\
(\mathrm{mm})\end{array}$ & $h_{\mathrm{w}} / t_{\mathrm{w}}$ & $b_{1} / t_{\mathrm{f}}$ & $\begin{array}{c}f_{\mathrm{yw}} \\
(\mathrm{MPa})\end{array}$ & $\begin{array}{c}f_{\mathrm{yf}} \\
(\mathrm{MPa})\end{array}$ & $\begin{array}{c}P_{\mathrm{n}} \\
(\mathrm{kN})\end{array}$ & \multicolumn{2}{c}{ EC3 classification } \\
\hline H1-0.2 & 300.3 & 159.8 & 6.14 & 7.64 & 46.42 & 10.1 & 283.08 & 260.08 & 200.4 & class 2 & clange 3 \\
$\mathrm{H} 2-0.2$ & 297.2 & 156.0 & 5.64 & 5.79 & 50.64 & 13.0 & 283.08 & 283.08 & 171.5 & class 2 & class 4 \\
$\mathrm{H} 3-0.2$ & 297.5 & 157.5 & 5.06 & 5.80 & 56.50 & 13.1 & 369.23 & 283.08 & 157.9 & class 3 & class 4 \\
H3-0.4 & 301.2 & 156.5 & 5.10 & 5.74 & 56.81 & 13.2 & 369.23 & 283.08 & 315.8 & class 3 & class 4 \\
H4-0.2 & 299.2 & 198.8 & 5.04 & 5.78 & 57.07 & 16.8 & 369.23 & 283.08 & 180.5 & class 3 & class 4 \\
H5-0.2 & 347.0 & 158.5 & 5.20 & 7.74 & 63.75 & 9.9 & 369.23 & 260.08 & 198.8 & class 3 & class 3 \\
\hline
\end{tabular}


The axial strains and transverse displacements of the web and flanges at buckling crest cross-section estimated by finite element analysis of the specimen are measured to monitor the local buckling.

The loading process is divided into two stages. First, the axial load $P$ is applied by the $1000 \mathrm{kN}$ hydraulic jack gradually until the nominal axial load $P_{\mathrm{n}}$ and maintained at this load level during the subsequent loading. Then, the horizontal load $F$ is applied by the $200 \mathrm{kN}$ servocontrolled hydraulic actuator adopting two different loading procedures successively: (a) force control loading procedure: the horizontal load is increased gradually until it reaches $60 \%$ of the ultimate load estimated by finite element analysis; (b) displacement control loading procedure: the horizontal displacement is increased gradually as the horizontal load reaches the maximum and then decreases to about $50 \sim 60 \%$ of the ultimate load. During the second loading stage, the horizontal displacement at specimen top is increased monotonically.

\section{Experimental results and observations}

\subsection{Local interactive buckling}

The axial strains and transverse displacements of the web and flanges at the buckling crest cross-section are measured and illustrated in Figure 3 and Figure 4, respectively. When the horizontal load $F$ reaches approximately $75 \mathrm{kN}$ for $\mathrm{H} 2-0.2$ and $90 \mathrm{kN}$ for H4-0.2, respectively, the compressive strains (measured by strain gauges S10 on the flange and S14 on the web stop increasing) begin decreasing and then develop tensile strains, and the transverse displacements (measured by displacement meters D5 and D7 on the opposite free ends of the flange) develop oppositely, both indicating that plate local buckling occurs within the web and flange in the compression zone, and the web and flange buckle simultaneously, which is identified as local interactive buckling. Similar axial strain curves and transverse displacement curves are drawn and the local interactive buckling can be tracked in other specimens.

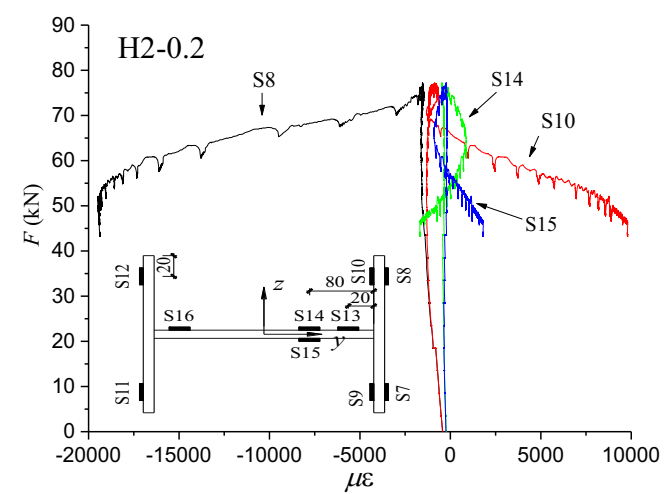

Figure 3. Axial strain curves at the buckling crest cross-section.

The interactive buckling of the web and flange is verified by the experimental failure modes of H1-0.2 and H2-0.2 illustrated in Figure 5, showing that both web and flange in the compression zone have obvious transverse displacements characterized by an evident longitudinal half wave. The distances between the buckling crest and the bottom of the specimen are $100 \mathrm{~mm}$ and $120 \mathrm{~mm}$, respectively, which are $40 \mathrm{~mm}$ and $20 \mathrm{~mm}$ lower than the buckling crest estimated by finite element analysis, respectively.
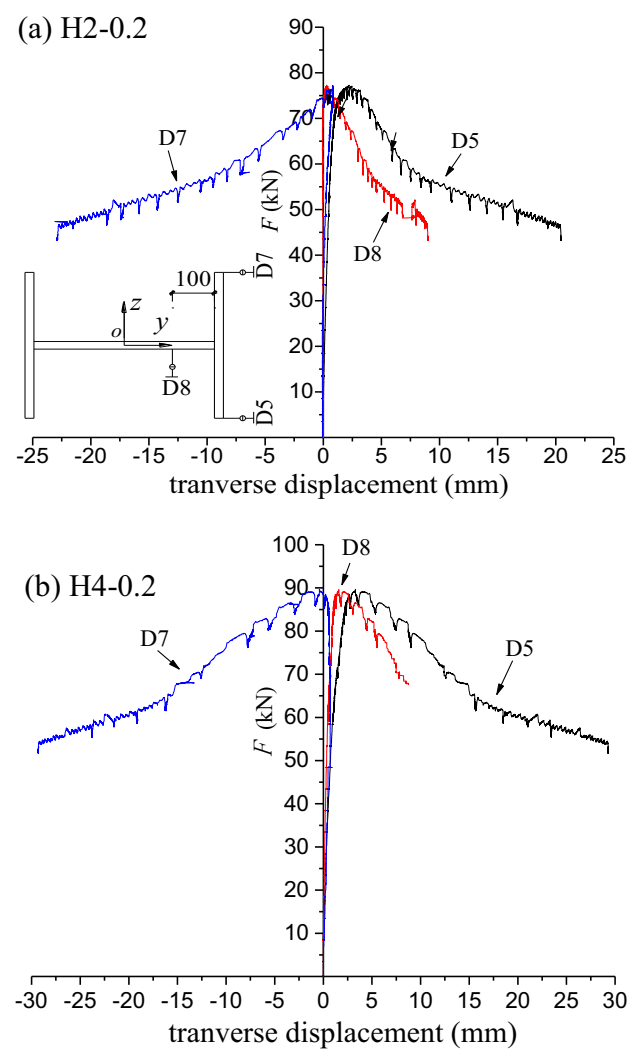

Figure 4. Transverse displacement curves at the buckling crest cross-section.
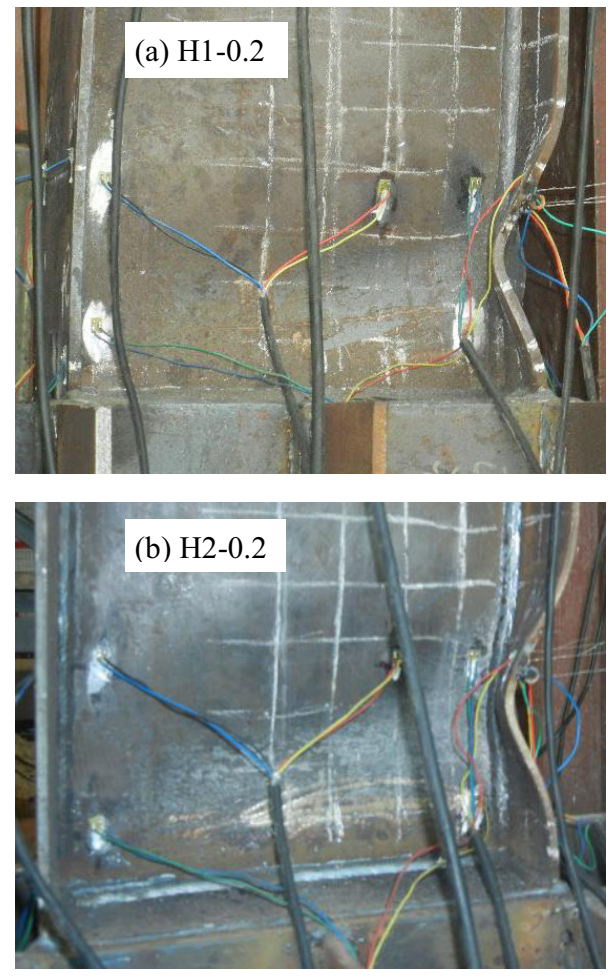

Figure 5. Experimental failure modes of the specimens. 
As illustrated in Figure 3 and Figure 4, different strain and displacement developing trends occur indicating the simultaneous local buckling of the web and flange in the compression zone and then the horizontal load $F$ decreases from its maximum, which indicates that it is the local interactive buckling that results in the decrease of the ultimate load capacity.

\subsection{Ultimate load and moment capacities}

The friction force between the sliding device and the hydraulic jack has been taken into account, which is estimated about $0.88 \%$ of the applied axial load, and the horizontal load $F$ is calibrated by deducting the friction force from the initial force recorded by the hydraulic actuator. After proper post-processing the test data, the horizontal load $F$ versus the in-plane displacement $\Delta$ curves are drawn first, based on which the normalized moment $M / M_{\mathrm{p}}$ versus $\theta$ curves are drawn, where $M_{\mathrm{p}}$ is the full-section plastic moment based on the measured parameters considering the effect of axial load. Since the plastic neutral axes of all the six specimens are verified to be located within the web plate, $M_{\mathrm{p}}$ can be calculated by

$$
\begin{gathered}
M_{\mathrm{p}}=f_{\mathrm{yf}} b_{\mathrm{f}} t_{\mathrm{f}}\left(h_{\mathrm{w}}+t_{\mathrm{f}}\right)+\alpha(1-\alpha) f_{\mathrm{yw}} t_{\mathrm{w}} h_{\mathrm{w}}^{2} \\
\alpha=\frac{P_{n}}{2 h_{w} t_{w} f_{\mathrm{yw}}}+0.5
\end{gathered}
$$

The normalized moment $M / M_{\mathrm{p}}$ versus $\theta$ curves of six specimens are shown in Figure 6, excluding the effect of the section dimensions and highlighting the effect of interaction between the flanges and web. The ultimate load capacities are extracted from $F$ versus $\Delta$ curves and $M / M_{\mathrm{p}}$ versus $\theta$ curves and listed in Table 3 , where $F_{\mathrm{u}}$ is the ultimate load, $M_{\mathrm{u}}=F_{\mathrm{u}} L$ is the ultimate moment capacity, $M_{\mathrm{u}} / M_{\mathrm{p}}$ is the normalized ultimate moment capacity, $\Delta_{\mathrm{u}}$ is the maximum horizontal displacement at the top of the specimen when the test stops, and $\theta_{\mathrm{u}}=\Delta_{\mathrm{u}} / L$

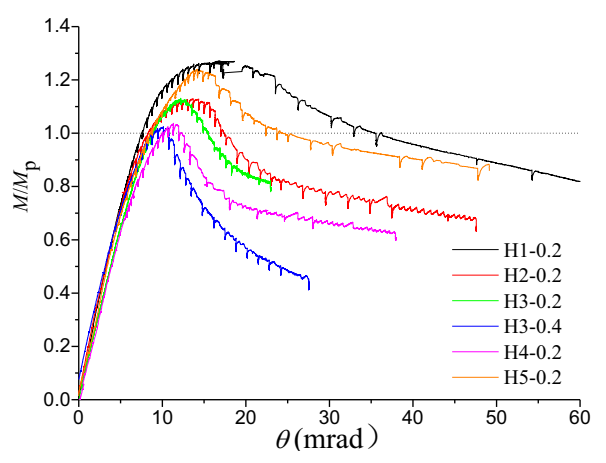

Figure 6. $M / M_{\mathrm{p}}$ versus $\theta$ curves of the specimens

Table 3. Ultimate load and moment capacities.

\begin{tabular}{cccccc}
\hline Specimen & $\begin{array}{c}F_{\mathrm{u}} \\
(\mathrm{kN})\end{array}$ & $\begin{array}{c}M_{\mathrm{u}} \\
(\mathrm{kN} \cdot \mathrm{m})\end{array}$ & $\begin{array}{c}M_{\mathrm{p}} \\
(\mathrm{kN} \cdot \mathrm{m})\end{array}$ & $M_{\mathrm{u}} / M_{\mathrm{p}}$ & $\begin{array}{c}\theta_{\mathrm{u}} \\
(\mathrm{mrad})\end{array}$ \\
\hline $\mathrm{H} 1-0.2$ & 102.39 & 153.59 & 122.45 & 1.25 & 60.97 \\
$\mathrm{H} 2-0.2$ & 76.59 & 114.89 & 102.47 & 1.12 & 47.60 \\
$\mathrm{H} 3-0.2$ & 83.18 & 124.77 & 110.27 & 1.13 & 22.99 \\
$\mathrm{H} 3-0.4$ & 69.16 & 103.74 & 101.41 & 1.02 & 27.56 \\
$\mathrm{H} 4-0.2$ & 87.48 & 131.22 & 129.56 & 1.01 & 37.97 \\
H5-0.2 & 128.34 & 192.51 & 155.85 & 1.24 & 49.15 \\
\hline
\end{tabular}

is maximum rotation. The ultimate moment capacities $M_{\mathrm{u}}$ of all specimens have exceeded the full-section plastic moment $M_{\mathrm{p}}$, indicating plasticity has been fully developed in all specimens and the strain hardening is achieved to a certain extent. The interaction between the web and flanges is considered to certainly play a positive role in enhancing the ultimate moment capacities of the beam-columns.

\section{Effects of three parameters}

\subsection{The effect of the axial compression ratio}

The effect of the axial compression ratio is illustrated in Figure 7 by comparing $M / M_{\mathrm{p}}$ versus $\theta$ curves of H3-0.2 vs H3-0.4. The normalized ultimate moment decreases remarkably as the axial compression ratio increases, indicating that the axial compression ratio has a significant effect on both the ultimate moment capacity and the normalized ultimate moment capacity of the beam-column, referring to Table 3 and Figure 7.

Since the flanges are the main components to sustain the moment around cross-section major axis, the occurrence of local buckling makes it difficult to develop plasticity further, resulting in the decrease of the ultimate moment capacity. Moreover, when subjected to larger axial compressive load, the web and flange in the compression zone is prone to develop plasticity earlier, resulting in earlier local buckling, sharper decrease of the ultimate moment capacity and more significant buckling interaction effect.

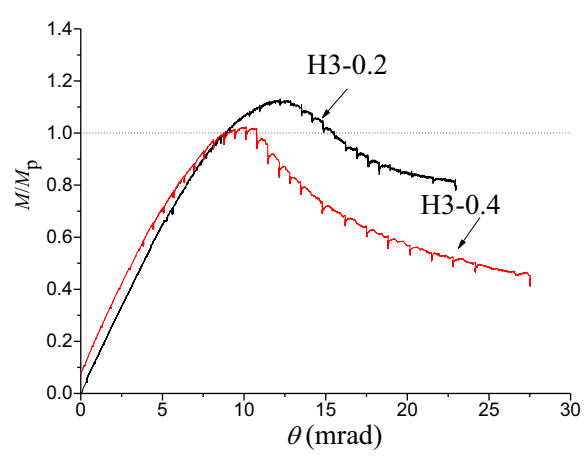

Figure 7. $M / M_{\mathrm{p}}$ versus $\theta$ curves affected by axial the compression ratio.

\subsection{The effect of the flange width-thickness ratio}

The effect of the flange width-thickness ratio is illustrated in Figure 8 by comparing $M / M_{\mathrm{p}}$ versus $\theta$ curves of H10.2 vs $\mathrm{H} 2-0.2$ and $\mathrm{H} 3-0.2$ vs $\mathrm{H} 4-0.2$. The normalized ultimate moment of the specimen with larger flange width-thickness ratio decreases more remarkably, indicating that flange width-thickness ratio has a significant effect on the normalized ultimate moment capacity.

Since the flanges are the major components of $\mathrm{H}$ section to sustain the moment around the cross-section major axis, flanges with larger width-thickness ratio are more liable to buckle, resulting in sharper decrease in the ultimate moment capacity, and the flange width-thickness ratio affects the normalized ultimate moment capacity directly. 

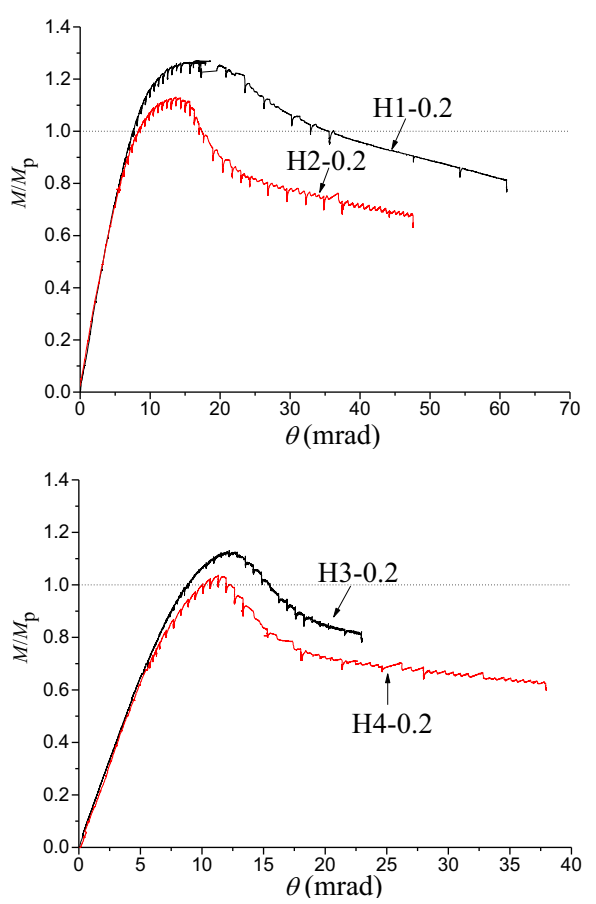

Figure 8. $M / M_{\mathrm{p}}$ versus $\theta$ curves affected by the flange widththickness ratio.

\subsection{The effect of the web height-thickness ratio}

The effect of the web height-thickness ratio is illustrated in Figure 9 by comparing the $M / M_{\mathrm{p}}$ versus $\theta$ curves of H1-0.2 vs H5-0.2 and H2-0.2 vs H3-0.2. It is observed that the web height-thickness ratio has little effect on the normalized ultimate moment capacity, but has some effect on the maximum rotation.
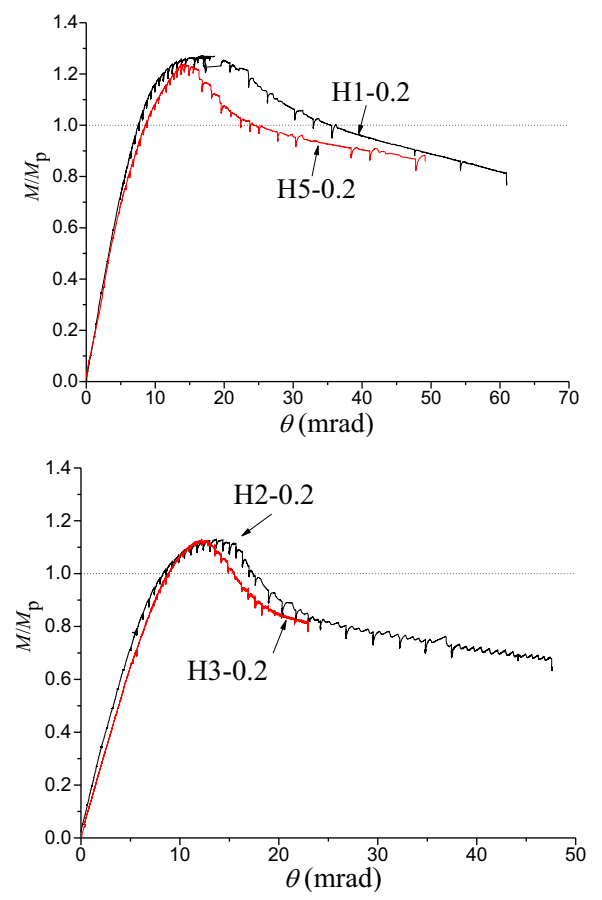

Figure 9. $M / M_{\mathrm{p}}$ versus $\theta$ curves affected by the web heightthickness ratio.

Since the web are the minor component of $\mathrm{H}$-section to sustain the moment around the cross-section major axis, though the web connecting the flanges can strengthen or weaken the flanges, the web height-thickness ratio affects the normalized ultimate moment capacity indirectly.

\section{Conclusions}

The elasto-plastic local interactive buckling performances of $\mathrm{H}$-section steel beam-columns are investigated through experimental studies. Some conclusions are as follows: The elasto-plastic local buckling of the web and flange in the compression zone occurs simultaneously and dominates failure mechanism resulting in the decrease of the moment capacity; the axial compression ratio and flange width-thickness ratio have significant effects on the normalized ultimate moment capacity of the beamcolumn, while the web height-thickness ratio has little effect on the normalized ultimate moment capacity, but has some effect on the maximum rotation.

Finite element parametric analyses are performed to investigate the effects of the axial compression ratio, the flange width-thickness ratio and the web height-thickness ratio in wider ranges on the ultimate moment capacities, and the finite element analysis models and results are validated by the experimental results, which will be presented in another paper.

\section{Acknowledgments}

The research was sponsored by The National Natural Science Foundation of China key project (No. 51038008) and was first reported in Jiang Zhou's dissertation for the degree of Master of Science [11]. The authors would also like to thank the project leader Professor Yi-yi Chen.

\section{References}

1. G.P. Mulligan, T. Pekoz, J. Struct. Eng. 113, 604 (1987)

2. S.F. Chen, Progr. Steel Build. Struct. 4, 3 (2002) (in Chinese)

3. W.X. Ren, Q.Y. Zeng, J. Struct. Eng. 123, 1210 (1997)

4. O. Bedair, Thin Walled Struct. 47, 768 (2009)

5. A.S. Hasham, K.J.R. Rasmussen, J. Constr. Steel Res. 58, 213 (2002)

6. X. Cheng, Y.Y. Chen, L.L. Pan, J. Constr. Steel Res. 88, 279 (2013)

7. X. Cheng, Y.Y. Chen, D.A. Nethercot, Eng. Struct. 49, 264 (2013)

8. T. Wang, K. Ikarashi, J. Asian Archit. Build. Eng. 10, 429 (2011)

9. A.H. Salem, M.El Aghoury, F.F.El Dib, M.T. Hanna, J. Constr. Steel Res. 60, 1193 (2004)

10. X. Cheng, Y.Y. Chen, Eng. Mech. 32, 419 (2015) (in Chinese)

11. J. Zhou, Master Dissert. Tongji Univ. (2012) (in Chinese)

12. Eurocode 3. Design of steel structures, Part 1.1: General rules and rules for buildings. BS-EN19931-1:2005, CEN, Brussels, 2005. 